\title{
Pengukuran Tingkat Polusi Cahaya dan Awal Waktu Subuh di OIF UMSU dengan Menggunakan Sky Quality Meter
}

\author{
Arwin Juli Rakhmadi, Hasrian Rudi Setiawan, dan Abu Yazid Raisal \\ Universitas Muhammadiyah Sumatera Utara \\ *E-mail: arwinjuli@umsu.ac.id
}

\begin{abstract}
Abstrak
Polusi cahaya merupakan masalah utama bagi kegiatan observasi di observatorium. Karena itu Observatorium Ilmu Falak Universitas Muhammadiyah Sumatera Utara (OIF UMSU) perlu mengukur tingkat polusi cahaya demi kelancaran observasi. Polusi cahaya dapat diketahui dengan cara mengukur tingkat kecerahan langit malam menggunakan Sky Quality Meter (SQM). Penelitian ini dilakukan dengan metode observasi. SQM dipasang pada tiga arah yaitu zenit, $45^{\circ}$ timur dan ufuk timur. Nilai kecerahan langit untuk SQM yang diarahkan ke ufuk timur memiliki nilai paling rendah dibandingkan dengan arah yang lain dikarenakan polusi cahaya yang tinggi di langit ufuk timur. Hasil penelitian menunjukkan nilai kecerahan langit dari SQM yang diarahkan ke zenit, $45^{\circ}$ timur dan ufuk timur menunjukkan nilai rata-rata 17,01 mpsas, 16,57 mpsas, dan 15,81 mpsas. Berdasarkan hasil penelitian dapat disimpulkan bahwa polusi cahaya di OIF UMSU sudah dominan. Awal waktu Subuh terjadi pada saat fajar nautikal dilihat dari ketinggian Matahari yang diperoleh oleh SQM yang diarahkan ke zenit, $45^{\circ}$ timur dan ufuk timur memiliki nilai rata-rata $9,78^{\circ}, 11,06^{\circ}$ dan $11,07^{\circ}$ di bawah horizon.
\end{abstract}

Kata kunci: Polusi cahaya, Awal waktu Subuh, Sky Quality Meter

\section{PENDAHULUAN}

Beberapa tahun belakangan ini, ada peningkatan terhadap penelitian tentang kecerahan langit malam. Peningkatan ini dapat dikaitkan dengan beberapa faktor yaitu semakin banyak orang yang menyadari dampak cahaya buatan terhadap ekologi dan kesehatan, ada peningkatan kualitas gambar dari luar angkasa, perubahan global dalam teknologi pencahayaan saat ini, dan semakin bertambahnya instrumen dan metode untuk mengukur cahaya pada intensitas cahaya bintang (Hänel et al., 2018). Mengukur kecerahan langit malam juga sangat penting untuk menjaga observatorium karena polusi cahaya merupakan masalah utama bagi kegiatan observasi di observatorium (Pramudya et al., 2019). Benda-benda langit dapat diamati dengan jelas apabila langit malam cerah. Langit malam cerah ditentukan oleh proporsi kuantitatif dari cakupan awan dan durasi waktu ketika tidak ada awan sepanjang malam (Zhang et al., 2015). Benda-benda langit menjadi semakin sulit diamati dikarenakan kondisi langit yang semakin terang akibat polusi cahaya yang semakin bertambah (Nurfarida et al., 2017). Pada umumnya manusia memiliki batas hanya dapat melihat bintang dengan magnitudo minimal 6 . Semakin terang langit semakin kecil nilai magnitudo bintang yang dapat diamati oleh mata manusia. Hal ini mengakibatkan daerah dengan polusi cahaya yang tinggi sulit untuk melihat bintang-bintang di langit.

Polusi cahaya dibagi menjadi polusi cahaya dalam ruangan dan luar ruangan (Rajkhowa, 2014). Pencahayaan luar ruangan biasanya digunakan untuk tujuan keselamatan, rekreasi dan dekorasi. Namun, sistem pencahayaan yang dirancang dengan buruk dan berlebihan menyebabkan adanya polusi cahaya. Polusi cahaya luar ruangan berasal dari lampu jalan, lampu neon, dan papan reklame yang menyala (Pun \& So, 2012). Permasalahan ini dialami oleh seluruh dunia, namun banyak negara belum mempunyai badan resmi yang bertugas untuk mengendalikan polusi cahaya (Herdiwijaya, 2016). Polusi cahaya dapat dikurangi dengan berbagai cara, salah satunya seperti mengadakan kegiatan Earth Hour yaitu mematikan lampu selama satu jam pada tanggal tertentu (Sukma et al., 2019).

Tingkat polusi cahaya dapat diketahui dengan cara mengukur tingkat kecerahan langit malam 
menggunakan alat bernama Sky Quality Meter (SQM). Kecerahan langit malam dapat dipengaruhi oleh beberapa faktor yaitu cahaya dari galaksi, cahaya zodiak, aurora, airglow malam, dan garis emisi senja (Hassan et al., 2014). Selain itu, kecerahan langit malam juga dipengaruhi oleh fase Bulan (Raisal et al., 2017). Fase bulan adalah penampakan wajah Bulan yang terlihat berbeda setaip saat yang disebabkan posisi relatif Bumi dan Matahari (Raisal, 2018).

Selain digunakaan untuk mengetahui tingkat polusi cahaya, SQM juga dapat digunakan untuk mengetahui awal waktu salat Subuh. Penelitian awal waktu salat Subuh di Indonesia mulai banyak dilakukan ketika ada majalah yang mengatakan bahwa awal waktu salat Subuh di Indonesia terlalu cepat bahkan sampai 24 menit. Waktu salat Subuh dimulai saat terbit fajar sadik dan berakhir saat Matahari terbit. Fajar sadik adalah saat garis putih yang seragam membentang secara horizontal di ufuk timur yang disebabkan pembiasan cahaya Matahari oleh atmosfer (Noor \& Hamdani, 2018). Waktu salat Subuh berbeda dengan waktu salat Zuhur, Asar dan Maghrib yang dapat ditentukan secara akurat dengan melihat panjang bayangan benda. Waktu salat Subuh dan Isya tidak dapat ditentukan dengan melihat bayangan benda karena Matahari berada di bawah horizon. Fajar sadik dapat dilihat secara langsung atau dapat ditentukan dengan mengukur perubahan kecerahan langit yang disebabkan pembiasan cahaya Matahari menggunakan SQM (Ahyar et al., 2018). Fajar sadik muncul menjelang Matahari terbit ketika tinggi Matahari berada sekitar $18^{\circ}$ di bawah horizon. Namun ada pendapat lain yang menyatakan bahwa fajar sadik muncul ketika tinggi Matahari $20^{\circ}$ di bawah horizon (Rahmadani, 2018). Fajar dalam astronomi dibedakan menjadi tiga berdasarkan ketinggian Matahari di bawah horizon yaitu fajar sipil, fajar nautikal, dan fajar astronomi. Ketinggian Matahari saat fajar sipil mulai dari horizon hingga $6^{\circ}$ di bawah horizon, ketinggian Matahari saat fajar nautikal mulai $6^{\circ}$ hingga $12^{\circ}$ di bawah horizon dan ketinggian Matahari saat fajar astronomi mulai $12^{\circ}$ hingga $18^{\circ}$ di bawah horizon (Herdiwijaya, 2016). Ketinggian Matahari dalam menentukan waktu Subuh berbeda-beda di berbagai negara seperti terlihat pada tabel 1 .

Tabel 1. Tinggi Matahari dalam menentukan awal waktu Subuh (Nor \& Zainuddin, 2012)

\begin{tabular}{clc}
\hline No & \multicolumn{1}{c}{ Konvensi } & $\begin{array}{c}\text { Ketinggian Matahari di } \\
\text { bawah horizon }\end{array}$ \\
\hline 1 & Shiah Ithna Ashari (Jaafari) & $16^{\circ}$ \\
2 & Islamic Society of North America (ISNA) & $15^{\circ}$ \\
3 & Muslim World League (MWL) & $18^{\circ}$ \\
4 & Umm Al-qura Makkah & $18,5^{\circ}$ \\
5 & Eqyptian General Authority of Survey & $19,5^{\circ}$ \\
6 & University of Islamic Science, Karachi & $18^{\circ}$ \\
7 & Malaysia & $20^{\circ}$ \\
\hline
\end{tabular}

Observatorium IImu Falak Universitas Muhammadiyah Sumatera Utara (OIF UMSU) merupakan salah satu yang berperan dalam pengembangan ilmu falak di Indonesia, khususnya di Sumatera Utara. Kegiatan yang dilakukan di tempat ini antara lain pengamatan benda-benda langit, pengamatan awal bulan, dan pengamatan fajar dan senja (Qorib et al., 2019). Idelanya, pengamatan benda langit dilakukan dalam kondisi langit gelap atau setara dengan nilai magnitudo 22 derajat. Polusi cahaya mengakibatkan nilai magnitudo langit semakin kecil yang menyebabkan benda-benda langit menjadi sulit untuk diamati (Nurfarida et al., 2017). Hal ini dapat berakibat pada kegiatan yang ada di OIF UMSU. Kegiatan lain yang dilakukan oleh OIF UMSU adalah pengamatan fajar dan syafak. Sebagai salah satu yang berperan dalam pengembangan ilmu falak di Indonesia, OIF UMSU merasa perlu untuk membuktikan apakah awal waktu Subuh di Indonesia terlalu cepat atau tidak. Hal ini penting untuk menjawab keresahan masyarakat karena masalah ini bersangkutan dengan ibadah.yang dilakukan setiap hari. Tingkat polusi cahaya dan awal waktu Subuh merupakan masalah yang menjadi fokus dalam penelitian ini.

\section{METODE}

Penelitian ini dilakukan dengan metode observasi. Pengukuran dilakukan di Observatorium 
IImu Falak Universitas Muhammadiyah Sumatera Utara yang beralamat di Jalan Denai No.70 Medan, Indonesia dan memiliki titik koordinat $3^{\circ} 43^{\prime}$ LU dan 98 $34^{\prime}$ BT. Kecerahan langit malam diukur dengan SQM. Perubahan kecerahan langit saat gerhana Matahari total juga dapat diukur dengan SQM (Pramudya \& Arkanuddin, 2016). Jenis SQM yang digunakan adalah SQM-LU dan SQM-LU-DL. Luaran bacaan dari alat ini mempunyai satuan mag/arcsec ${ }^{2}$ (mpsas). Kondisi langit malam yang paling gelap yang dapat terdeteksi SQM adalah $24 \mathrm{mag} / \mathrm{arsec}^{2}$ atau setara dengan bintang dengan magnitudo 7,3 yang dapat dilihat oleh mata manusia. Medan pandang SQM-LU dan SQM-LU-DL untuk Full Width Half Maximum (FWHM) adalah 20 (Rochman et al., 2019). berikut:

Pengukuran kecerahan langit menggunakan SQM mengikuti prosedur penelitian sebagai

1. SQM dipasang pada tiga arah yang berbeda yaitu ke arah zenit, $45^{\circ}$ timur, dan ufuk timur seperti terlihat pada gambar 1 .

2. SQM dihubungkan pada komputer dengan menggunakan kabel USB.

3. SQM diatur untuk merekam data kecerahan langit setiap 2 detik.

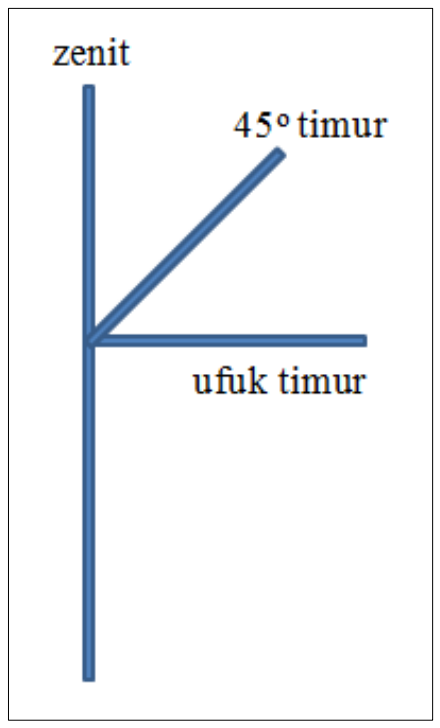

Gambar 1. Desain variasi sudut SQM

Setiap sudut merekam data selama enam bulan. Namun data yang diambil hanya pada hari dimana cahaya bulan tidak mempengaruhi kecerahan langit malam. Data dari SQM diolah menggunakan metode moving average untuk menentukan awal waktu Subuh. Metode moving average digunakan untuk mengurangi derau dalam data sehingga dapat memudahkan dalam menentukan waktu ketika terjadi awal peralihan dari malam ke pagi hari (Raisal \& Pramudya, 2019).

\section{HASIL DAN PEMBAHASAN}

Hasil

Data dikumpulkan dari Januari 2019 hingga Januari 2020. Karena keterbatasan jumlah SQM, pengambilan data tidak dilakukan pada waktu yang sama. Data kecerahan langit untuk SQM yang diarahkan ke ufuk timur diambil dari bulan Januari hingga Juni 2019. Sedangkan Data kecerahan langit untuk SQM yang diarahkan ke zenit dan $45^{\circ}$ timur diambil pada bulan Agustus 2019 hingga Januari 2020. Hari yang dipilih adalah hari saat bulan tidak menyinari malam hari sehingga cahaya bulan tidak mempengaruhi kecerahan langit.

Gambar 2 menunjukkan grafik kecerahan langit pada tanggal 3 September 2019 arah zenit dan arah $45^{\circ}$ timur. Sumbu $X$ menunjukkan waktu dan sumbu $Y$ menunjukkan nilai kecerahan langit. 

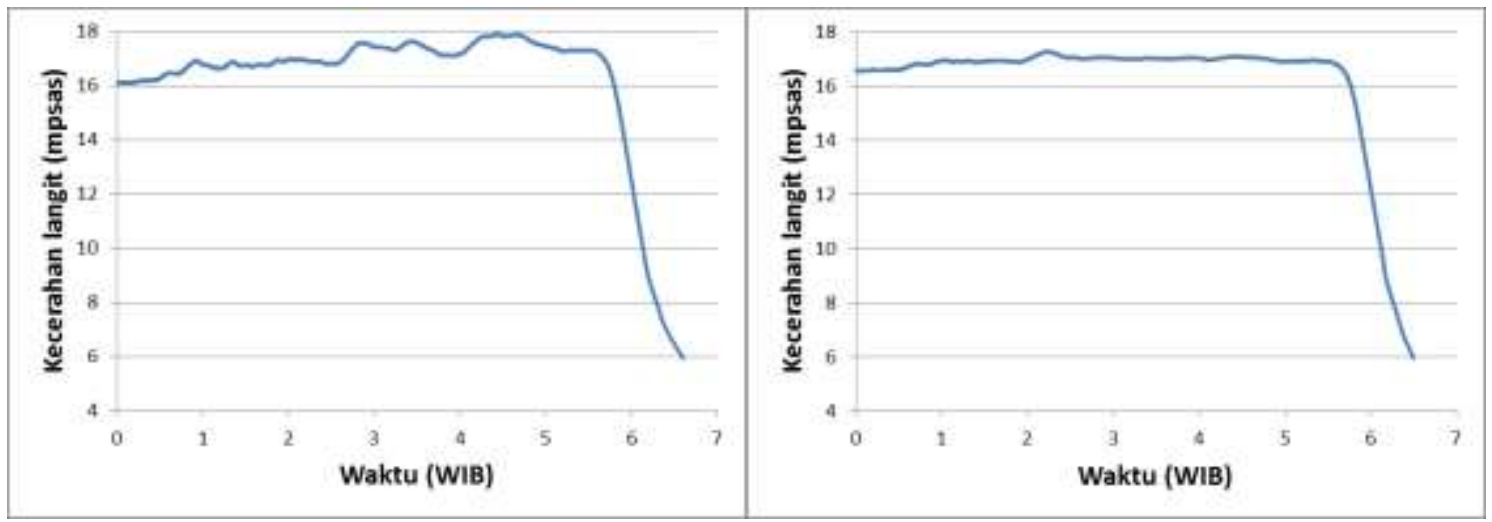

Gambar 2. Grafik kecerahan langit pada tanggal 3 September 2019 arah zenit (kiri) dan arah 45 timur (kanan)

Gambar 3 menunjukkan grafik kecerahan langit pada tanggal 8 Januari 2019 arah ufuk timur. Dapat dilihat grafik yang dihasilkan lebih rata daripada gambar 2. Namun nilai kecerahan langit yang diperoleh lebih kecil dibandingkan dengan gambar 2.

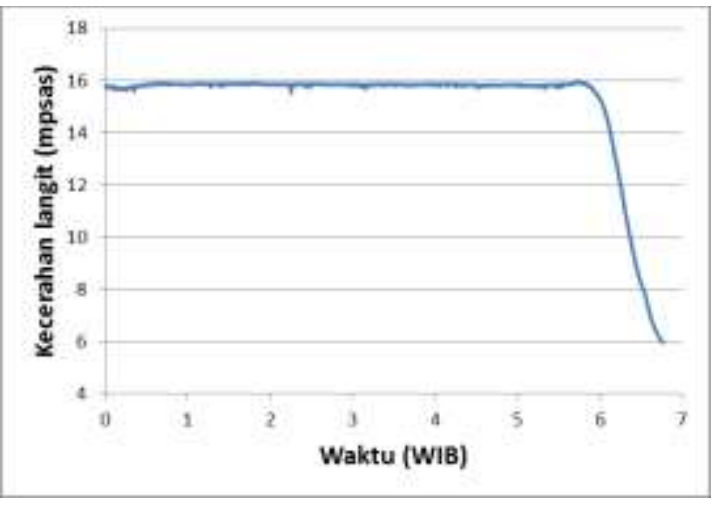

Gambar 3. Grafik kecerahan langit pada tanggal 8 Januari 2019 arah ufuk timur

Nilai kecerahan langit selama satu malam kemudian dicari rata-ratanya. Nilai yang dipilih untuk dirata-ratakan adalah dari tengah malam hingga pukul 05.00 WIB. Rata-rata kecerahan langit yang diperoleh dapat dilihat pada tabel 2.

Tabel 2. Rata-rata kecerahan langit yang diperoleh

\begin{tabular}{lccc}
\hline Tanggal & $\begin{array}{c}\text { Ufuk timur } \\
\text { (mpsas) }\end{array}$ & $\begin{array}{c}45^{\circ} \text { timur } \\
\text { (mpsas) }\end{array}$ & $\begin{array}{c}\text { Zenit } \\
\text { (mpsas) }\end{array}$ \\
\hline $8 / 1 / 2019$ & 15,84 & - & - \\
$7 / 2 / 2019$ & 15,78 & - & - \\
$8 / 3 / 2019$ & 15,83 & - & - \\
$11 / 4 / 2019$ & 15,79 & - & - \\
$6 / 5 / 2019$ & 15,88 & - & - \\
$5 / 6 / 2019$ & 15,74 & - & 17,31 \\
$4 / 8 / 2019$ & - & 16,78 & 17,04 \\
$3 / 9 / 2019$ & - & 16,93 & 16,46 \\
$6 / 10 / 2019$ & - & 15,39 & 16,46 \\
$1 / 11 / 2019$ & - & 16,58 & 17,70 \\
$4 / 12 / 2019$ & - & 16,99 & 17,66 \\
$1 / 1 / 2020$ & - & 16,76 & $\mathbf{1 7 , 0 1}$ \\
\hline Rata-rata & $\mathbf{1 5 , 8 1}$ & $\mathbf{1 6 , 5 7}$ & \\
\hline
\end{tabular}

Tabel 3 menunjukkan nilai kecerahan langit maksimum. Nilai ini diperoleh dengan mencari nilai 
kecerahan langit tertinggi yang terekam oleh SQM dari tengah malam hingga Matahari terbit. Nilai kecerahan langit tertinggi diperoleh oleh SQM yang diarahkan ke zenit pada tanggal 4 Desember 2019 dengan nilai 18,72 mpsas.

Tabel 3. Nilai kecerahan langit maksimum

\begin{tabular}{lccc}
\hline Tanggal & $\begin{array}{c}\text { Ufuk timur } \\
\text { (mpsas) }\end{array}$ & $\begin{array}{c}45^{\circ} \text { timur } \\
\text { (mpsas) }\end{array}$ & $\begin{array}{c}\text { Zenit } \\
\text { (mpsas) }\end{array}$ \\
\hline $8 / 1 / 2019$ & 15,98 & - & - \\
$7 / 2 / 2019$ & 15,90 & - & - \\
$8 / 3 / 2019$ & 15,95 & - & - \\
$11 / 4 / 2019$ & 15,93 & - & - \\
$6 / 5 / 2019$ & 16,01 & - & - \\
$5 / 6 / 2019$ & 15,82 & - & - \\
$4 / 8 / 2019$ & - & 16,95 & 17,63 \\
$3 / 9 / 2019$ & - & 17,25 & 17,91 \\
$6 / 10 / 2019$ & - & 16,05 & 17,73 \\
$1 / 11 / 2019$ & - & 17,12 & 17,13 \\
$4 / 12 / 2019$ & - & 17,55 & 18,72 \\
$1 / 1 / 2020$ & - & 17,16 & 18,38 \\
\hline
\end{tabular}

Awal waktu Subuh ditentukan pada saat terjadi penurunan nilai kecerahan langit secara bertahap. Waktu saat nilai turun secara bertahap dihitung menggunakan moving average. Awal waktu salat Subuh yang dihitung menggunakan moving average dapat dilihat pada tabel 4.

Tabel 4. Awal waktu salat Subuh menggunakan moving average

\begin{tabular}{lccc}
\hline Tanggal & $\begin{array}{c}\text { Ufuk timur } \\
(\text { WIB })\end{array}$ & $\begin{array}{c}45^{\circ} \text { timur } \\
(\text { WIB })\end{array}$ & $\begin{array}{c}\text { Zenit } \\
(\text { WIB })\end{array}$ \\
\hline $8 / 1 / 2019$ & 05.53 & - & - \\
$7 / 2 / 2019$ & 05.57 & - & - \\
$8 / 3 / 2019$ & 05.57 & - & - \\
$11 / 4 / 2019$ & 05.45 & - & - \\
$6 / 5 / 2019$ & 05.41 & - & - \\
$5 / 6 / 2019$ & 05.38 & - & - \\
$4 / 8 / 2019$ & - & 05.31 & 05.30 \\
$3 / 9 / 2019$ & - & 05.35 & 05.34 \\
$6 / 10 / 2019$ & - & 05.32 & 05.23 \\
$1 / 11 / 2019$ & - & 05.31 & 05.35 \\
$4 / 12 / 2019$ & - & 05.41 & 05.43 \\
$1 / 1 / 2020$ & - & 05.46 & 05.51 \\
\hline
\end{tabular}

Waktu salat Subuh sangat identik dengan ketinggian Matahari di bawah horizon. Penentuan ketinggian Matahari pada saat awal waktu Subuh dihitung menggunakan aplikasi Accurate Times. Ketinggian Matahari saat awal waktu Subuh dapat dilihat pada tabel 5.

Tabel 5. Ketinggian Matahari pada saat awal waktu Subuh

\begin{tabular}{lccc}
\hline Tanggal & Ufuk timur & $45^{\circ}$ timur & zenit \\
\hline $8 / 1 / 2019$ & $10,23^{\circ}$ & - & - \\
$7 / 2 / 2019$ & $11,06^{\circ}$ & - & - \\
$8 / 3 / 2019$ & $10,05^{\circ}$ & - & - \\
$11 / 4 / 2019$ & $9,65^{\circ}$ & - & - \\
$6 / 5 / 2019$ & $8,78^{\circ}$ & - & - \\
$5 / 6 / 2019$ & $8,93^{\circ}$ & - & - \\
$4 / 8 / 2019$ & - & $13,36^{\circ}$ & $13,49^{\circ}$ \\
$3 / 9 / 2019$ & - & $11,91^{\circ}$ & $11,97^{\circ}$ \\
$6 / 10 / 2019$ & - & $10,69^{\circ}$ & $12,96^{\circ}$ \\
$1 / 11 / 2019$ & - & $10,01^{\circ}$ & $9,16^{\circ}$ \\
$4 / 12 / 2019$ & - & $9,22^{\circ}$ & $8,87^{\circ}$ \\
$1 / 1 / 2020$ & - & $11,17^{\circ}$ & $9,94^{\circ}$ \\
\hline Rata-rata & $\mathbf{9 , 7 8 ^ { \circ }}$ & $\mathbf{1 1 , 0 6 ^ { \circ }}$ & $\mathbf{1 1 , 0 7 ^ { \circ }}$ \\
\hline
\end{tabular}




\section{Pembahasan}

Waktu yang dipilih dimulai dari tengah malam untuk mengurangi pengaruh dari aktifitas masyarakat di malam hari. Pada gambar 2 nilai kecerahan langit malam untuk SQM yang diarahkan ke zenit terlihat tidak rata yang dapat diakibatkan oleh pengaruh awan di langit sehingga menghasilkan noise pada saat pengambilan data. Sementara untuk SQM yang diarahkan ke $45^{\circ}$ timur, nilai kecerahan langit malam terlihat lebih rata walaupun ada sedikit noise. Meskipun terlihat lebih rata namun nilai kecerahan langit maksimum yang diperoleh lebih rendah daripada SQM yang diarahkan ke zenit. Pengaruh awan di langit arah $45^{\circ}$ lebih banyak dan stabil dari pada di zenit sehingga nilai kecerahan langit maksimum di zenit lebih tinggi.

Grafik yang diperoleh SQM yang diarahkan ke ufuk timur lebih rata dibandingkan dengan SQM yang diarahkan ke zenith dan $45^{\circ}$ timur, namun nilai kecerahan langit yang diperoleh lebih rendah $\mathrm{Hal}$ ini disebabkan langit arah ufuk timur memiliki polusi yang lebih besar dibandingkan dengan langit arah zenit dan $45^{\circ}$ timur. Selain itu medan pandang SQM yang besarnya $20^{\circ}$ juga berpengaruh dalam pengambilan data. SQM yang diarahkan ke ufuk timur pada jarak tertentu akan langsung merekam cahaya dari lampu rumah yang berada di timur lokasi pengambilan data sehingga nilai kecerahan langit yang diperoleh menjadi rendah.

Nilai kecerahan langit rata-rata untuk SQM yang diarahkan ke ufuk timur, $45^{\circ}$ timur dan zenit adalah 15,81 mpsas, 16,57 mpsas dan 17,01 mpsas. Berdasarkan skala Bortle, lokasi OIF UMSU berada pada katagori kelima ( $<18,0$ mpsas) yang menunjukkan bahwa polusi cahaya sudah dominan sehingga hanya planet-planet terang yang dapat dilihat. Skala Bortle merupakan skala yang digunakan untuk menentukan kecerahan langit. Skala Bortle dibagi menjadi 9 kelas yaitu, dari excellent dark-sky site, typical truly dark site, rural sky, rural/suburban transition, suburban sky, bright suburban sky, suburban/urban transition, city sky, dan inner-city sky (Bortle, 2001). Skala Bortle dapat disederhanakan menjadi lima kategori yaitu kategori pertama (>21,3 mpsas) galaksi Bimsa Sakti dan cahaya zodiak bisa dilihat, kategori kedua (20,4 - 21,3 mpsas) galaksi Bima Sakti dan cahaya zodiak bisa dilihat di waktu tertentu, kategori ketiga (19,1 - 20,4 mpsas) galaksi Bima Sakti hanya terlihat di zenit dan polusi cahaya mencapai $35^{\circ}$ dari horizon, kategori keempat (18,0 - 19,1 mpsas) cahaya zodiak tidak terlihat dan galaksi Bima Sakti terlihat di arah zenit pada waktu tertentu, dan kategori kelima (<18,0 mpsas) polusi cahaya sudah dominan dan hanya planet-planet terang yang dapat terlihat (Herdiwijaya, 2019).

Tingginya polusi cahaya di lokasi observatorium mengakibatkan benda langit yang dapat diamati menjadi lebih sedikit. Hal ini tidak hanya dialami oleh OIF UMSU, observatorium lain seperti observatorium Bosscha di kabupaten Bandung juga terpengaruh oleh polusi cahaya sehingga Lembaga Penerbangan dan Antariksa Nasional (LAPAN) berencana membangun observatorium baru di Kupang yang dianggap lokasi tersebut masih minim polusi cahaya (Nurfarida et al., 2017). Beberapa observatorium di Amerika Serikat melakukan pencarian lokasi observatorium yang baru karena lokasi sebelumnya mengalami masalah dengan polusi cahaya (Luginbuhl et al., 2009).

Mendekati pukul 06.00 WIB pada gambar 2 dan 3 tampak terjadi penurunan nilai kecerahan langit secara bertahap. Hal ini disebabkan sinar matahari mulai dibiaskan ke langit oleh atmosfer sehingga mempengaruhi nilai kecerahan langit meskipun Matahari masih di bawah horizon. Pada saat terjadi penurunan secara bertahap ini ditentukan sebagai saat munculnya fajar sadik atau awal waktu salat Subuh. Ketinggian Matahari untuk SQM yang diarahkan ke ufuk timur, $45^{\circ}$ timur, dan zenit memiliki nilai rata-rata $9,78^{\circ}, 11,06^{\circ}$ dan $11,07^{\circ}$ di bawah horizon. Hal ini menunjukkan bahwa awal waktu Subuh terjadi pada saat fajar nautikal. Pemerintah Indonesia yang diwakili oleh Kementerian Agama menggunakan ketinggian Matahari $20^{\circ}$ di bawah horizon sebagai penentu awal waktu salat Subuh (Mughits, 2014). Berdasarkan hasil yang diperoleh SQM menunjukkan bahwa awal waktu Subuh di Indonesia terlalu cepat. Beberapa penelitian sebelumnya juga menemukan bahwa fajar sadik yang menjadi acuan awal waktu Subuh terdeteksi pada saat ketinggian Matahari 
$17^{\circ}$ di bawah horizon (Herdiwijaya, 2019; Noor \& Hamdani, 2018). Ketinggian Matahari untuk menentukan awal waktu Subuh yang diperoleh di OIF UMSU paling tinggi bernilai 11,070 di bawah horizon dengan SQM diarahkan ke zenit. Hal ini bisa jadi disebabkan karena lokasi OIF UMSU yang berada di daerah dengan tingkat polusi cahaya yang tinggi sehingga nilai yang diperoleh lebih rendah.

\section{PENUTUP}

Berdasarkan hasil yang diperoleh maka dapat diambil beberapa kesimpulan yaitu nilai kecerahan langit untuk SQM yang diarahkan ke ufuk timur memiliki nilai paling rendah dibandingkan dengan arah yang lain dikarenakan polusi cahaya yang tinggi di langit ufuk timur. Nilai kecerahan langit dari SQM yang diarahkan ke zenit, $45^{\circ}$ timur dan ufuk timur menunjukkan nilai rata-rata 17,01 mpsas, 16,57 mpsas, dan 15,81 mpsas. Berdasarkan skala Bortle, polusi cahaya di OIF UMSU sudah dominan sehingga benda-benda langit yang dapat diamati menjadi lebih sedikit. Awal waktu Subuh terjadi pada saat fajar nautikal dilihat dari ketinggian Matahari yang diperoleh oleh SQM yang diarahkan ke zenit, $45^{\circ}$ timur dan ufuk timur memiliki nilai rata-rata $9,78^{\circ}, 11,06^{\circ}$ dan $11,07^{\circ}$ di bawah horizon. Hal ini menunjukkan bahwa awal waktu Subuh di Indonesia yang mengacu pada ketinggian Matahari $20^{\circ}$ di bawah horizon lebih cepat daripada yang seharusnya.

\section{DAFTAR PUSTAKA}

Ahyar, M., Pramudya, Y., Raisal, A. Y., \& Okimustava. (2018). Penentuan Awal Waktu Subuh Menggunakan Sky Quality Meter pada Variasi Deklinasi Matahari. Prosiding SNFA (Seminar Nasional Fisika Dan Aplikasinya), 184-189.

Bortle, J. E. (2001). Introducing the Bortle Dark-Sky Scale. Sky \& Telescope, 101(2), 126-130.

Hänel, A., Posch, T., Ribas, S. J., Aubé, M., Duriscoe, D., Jechow, A., Kollath, Z., Lolkema, D. E., Moore, C., Schmidt, N., Spoelstra, H., Wuchterl, G., \& Kyba, C. C. M. (2018). Measuring Night Sky Brightness: Methods and Challenges. Journal of Quantitative Spectroscopy \& Radiative Transfer, 205, 278-290. https://doi.org/10.1016/j.jqsrt.2017.09.008

Hassan, A. H., Abdel-Hadi, Y. A., Issa, I. A., \& Hassanin, N. Y. (2014). Naked Eye Observations for Morning Twilight at Different Sites in Egypt. NRIAG Journal of Astronomy and Geophysics, 3, 23-26.

Herdiwijaya, D. (2016). Sky Brightness and Twilight Measurements at Jogyakarta City, Indonesia. Journal of Physics: Conference Series, 771, 1-4. https://doi.org/10.1088/1742$6596 / 771 / 1 / 012033$

Herdiwijaya, D. (2019). Waktu Subuh: Tinjauan Pengamatan Astronomi. Jurnal Tarjih, 14(1), 51-64.

Luginbuhl, C. B., Walker, C. E., \& Wainscoat, R. J. (2009). Lighting and Astronomy. Physics Today, 62(12), 32-37. https://doi.org/10.1063/1.3273014

Mughits, A. (2014). Problematika Jadwal Waktu Salat Subuh di Indonesia. Asy-Syir'ah: Jurnal IImu Syari'ah Dan Hukum, 48(2), 467-487.

Noor, L. A. H., \& Hamdani, F. F. R. S. (2018). The Dawn Sky Brightness Observations in the Preliminary Shubuh Prayer Time. QIJIS: Qudus International Journal of Islamic Studies, 6(1), 25-38.

Nor, S. A. M., \& Zainuddin, M. Z. (2012). Sky Brightness for Determination of Fajr and Isha Prayer by Using Sky Quality Meter. International Journal of Scientific \& Engineering Research, 3(8), 1-3.

Nurfarida, L., Yusup, P. M., \& Komariah, N. (2017). Tingkat Pengetahuan Masyarakat Sekitar Observatorium Bosscha Lembang Mengenai Polusi Cahaya. Jurnal Kajian Informasi Dan Perpustakaan, 5(1), 13-22. https://doi.org/10.24198/jkip.v5i1.11327

Pramudya, Y., \& Arkanuddin, M. (2016). The Sky Brightness Measurement During the 2016 Solar Eclipse in Ternate. Journal of Physics: Conference Series, 771, 1-4. https://doi.org/10.1088/1742-6596/771/1/012013

Pramudya, Y., Budi, K. S., Okimustava, \& Muchlas. (2019). Preliminary Study on Relation Between Temperature, Humidity and Night Sky Brightness in Yogyakarta. Journal of Physics: Conference Series, 1231, 1-7. https://doi.org/10.1088/1742-6596/1231/1/012004

Pun, C. S. J., \& So, C. W. (2012). Night-Sky Brightness Monitoring in Hong Kong A City-Wide Light Pollution Assessment. Environmental Monitoring and Assessment, 184, 2537-2557. 
https://doi.org/10.1007/s10661-011-2136-1

Qorib, M., Zailani, Radiman, Amrizal, \& Rakhmadi, A. juli. (2019). Peran dan Kontribusi OIF UMSU dalam Pengenalan IImu Falak di Sumatera Utara. Jurnal Pendidikan Islam, 10(2), 133-141.

Rahmadani, D. (2018). Telaah Rumus Perhitungan Waktu Salat: Tinjauan Parameter dan Algoritma. Al-Marshad: Jurnal Astronomi Islam Dan Ilmu-IImu Berkaitan, 4(2), 172-186.

Raisal, A. Y. (2018). Berbagai Konsep Hilal di Indonesia. Al-Marshad: Jurnal Astronomi Islam Dan IImu-IImu Berkaitan, 4(2), 146-155. https://doi.org/10.30596/jam.v4i2.2478

Raisal, A. Y., \& Pramudya, Y. (2019). Pemanfaatan Metode Moving Average dalam Menentukan Awal Waktu Salat Subuh Menggunakan Sky Quality Meter (SQM). Al-Marshad: Jurnal Astronomi Islam Dan IImu-IImu Berkaitan, 5(1), 1-13. https://doi.org/10.30596/jam.v5i1.3121

Raisal, A. Y., Pramudya, Y., Okimustava, \& Muchlas. (2017). The Moon Phases Influence on the Beginning of Astronomical Dawn Determination in Yogyakarta. International Journal of Science and Applied Science: Conference Series, 2(1), 1-7. https://doi.org/10.20961/ijsascs.v2i1.16664

Rajkhowa, R. (2014). Light Pollution and Impact of Light Pollution. International Journal of Science and Research (IJSR), 3(10), 861-867.

Rochman, A. A., Herdiwijaya, D., \& Setyanto, H. (2019). Tingkat Kepercayaan Fitting Polinomial Kurva Gradien Data SQM untuk Menentukan Kemunculan Fajar. Journal of Multidisciplinary Academic, 3(2), 27-31.

Sukma, M., Pramudya, Y., Muchlas, \& Okimustava. (2019). Night Sky Brightness Measurement During the March 2018 Earth Hour in Yogyakarta. Journal of Physics: Conference Series, 1231, 1-5. https://doi.org/10.1088/1742-6596/1231/1/012003

Zhang, J.-C., Ge, L., Lu, X.-M., Cao, Z.-H., Chen, X., Mao, Y.-N., \& Jiang, X.-J. (2015). Astronomical Observing Conditions at Xinglong Observatory from 2007 to 2014. Publications of the Astronomical Society of the Pacific, 127, 1292-1306. 